JGG 2021;69:147-154

doi: $10.36150 / 2499-6564-N 307$

\title{
Clinical characteristics and impact of treatment gap of fragility fractures in Colombia: experience of 10 Fracture Liaison Services (FLS)
}

Adriana Medina', Geraldine Altamar², Daniel G. Fernández-Ávila³, Jaime Leal', Edgar Castro ${ }^{5}$, Alejandra Rivera ${ }^{6}$, Amparo Gómez ${ }^{7}$, Luisa García ${ }^{8}$, Andrés Lancheros ${ }^{9}$, Rodolfo Páez ${ }^{10}$, Lina Vélez ${ }^{11}$, María Claudia Rivera ${ }^{12}$, Walter Chaparro ${ }^{13}$, Daniel Suárez ${ }^{14}$, César Rodríguez ${ }^{15}$, Viviana Filizzola ${ }^{16}$, Saúl Martínez ${ }^{17}$, Emilio Riveros $^{18}$, Carlos Olarte ${ }^{19}$, Diana Morales ${ }^{20}$, Oscar Rosero ${ }^{21}$, Carlos Alberto Castro ${ }^{22}$

${ }^{1}$ Asociación Colombiana de Osteoporosis y Metabolismo Mineral (ACOMM), Endocrinology Service, Hospital de San José, Fundación Universitaria de Ciencias de la Salud, Bogotá, Colombia; ${ }^{2}$ Geriatrics Service, Hospital Universitario del Valle, Cali, Colombia; ${ }^{3}$ Rheumatology Unit, Hospital Universitario San Ignacio, Pontificia Universidad Javeriana, Bogotá, Colombia; ${ }^{4}$ Orthopedics Service, Hospital Universitario de La Samaritana, Bogotá, Colombia; ${ }^{5}$ Geriatrics Service, Hospital de Caldas, Manizales, Colombia; ${ }^{6}$ Endocrinology Service, Hospital de San José, Bogotá, Colombia; ${ }^{7}$ Orthopedics Service, Hospital Universitario de La Samaritana, Bogotá, Colombia; ${ }^{8}$ Orthopedics Service, Hospital Universitario de La Samaritana, Bogotá, Colombia; ${ }^{9}$ Endocrinology Service, Hospital Universitario de La Samaritana, Bogotá, Colombia; ${ }^{10}$ Orthopedics Service, Hospital de San José, Fundación Universitaria de Ciencias de la Salud, Bogotá, Colombia; ${ }^{11}$ Orthopedics Service, Hospital Universitario San Vicente Fundación, Medellín, Colombia; ${ }^{12}$ Endocrinology Service, Hospital Universitario Clínica San Rafael, Bogotá, Colombia; ${ }^{13}$ Endocrinology Service, Hospital Universitario Clínica San Rafael, Bogotá, Colombia; ${ }^{14}$ Gynecology and Obstetrics Service, Hospital Universitario Clínica San Rafael, Bogotá, Colombia; ${ }^{15}$ Orthopedics Service, Hospital San Blas,

Received: October 22, 2020

Accepted: March 15, 2021

\section{Correspondence}

\section{Adriana Medina}

Asociación Colombiana de Osteoporosis y Metabolismo Mineral (ACOMM), Endocrinology Service, Hospital de San José, Fundación Universitaria de Ciencias de la Salud, Kr 19\# 8A32 Bogotá, Colombia

E-mail: adrimedor@hotmail.com

How to cite this article: Medina $A$, Altamar G, Fernández-Ávila DG, et al. Clinical characteristics and impact of treatment gap of fragility fractures in CoIombia: experience of 10 Fracture Liaison Services (FLS). Journal of Gerontology and Geriatrics 2021;69:147-154. https://doi. org/10.36150/2499-6564-N307

(C) Copyright by Società Italiana

di Gerontologia e Geriatria (SIGG)

\section{(c) (1) () $(-)$}

\section{OPEN ACCESS}

This is an open access article distributed in accordance with the CC-BY-NC-ND (Creative Commons Attribution-NonCommercial-NoDerivatives 4.0 International) license. The article can be used by giving appropriate credit and mentioning the license, but only for non-commercial purposes and only in the original version. For further information: https://creativecommons.org/licenses/by-nc-nd/4.0/deed.en
Bogotá, Colombia; ${ }^{16}$ Endocrinology Service, Hospital San Blas. Bogotá, Colombia; ${ }^{17}$ Orthopedics Service, Hospital Santa Clara, Bogotá, Colombia; ${ }^{18}$ Orthopedics Service, Hospital Santa Clara, Bogotá, Colombia; ${ }^{19}$ Orthopedics Service, Hospital Universitario Fundación Santa Fe de Bogotá, Bogotá, Colombia; ${ }^{20}$ Geriatrics Service, Hospital Universitario Fundación Santa Fe de Bogotá, Bogotá, Colombia; ${ }^{21}$ Asociación Colombiana de Osteoporosis y Metabolismo Mineral (ACOMM);

${ }^{22}$ SIIES Consultores SAS. Fundación Universitaria de Ciencias de la Salud, Bogotá, Colombia

Background \& aims. Fragility fractures are those caused by low-energy trauma or falls from standing height. The mortality after the first year of suffering a hip fracture ranges from 15 to $30 \%$. This problem has been addressed through the creation of interdisciplinary programs for fragility fracture early diagnosis and prevention. Describing the clinical characteristics of a cohort of patients diagnosed with fragility fractures in 10 fracture liaison services in Colombia.

Methods. Led by the Asociación Colombiana de Osteoporosis y Metabolismo Mineral, this is a cross-sectional descriptive study, in patients with a diagnosis of fragility fracture in 10 fracture liaison services. Demographic and clinical variables were described for one year from the diagnosis of the fracture.

Results. were analyzed 1699 records of patient fractures between 50 and 101 years of age, 1334 were women (76.5\%), 581/1484 (39.1\%) had previous fragility fractures, $570 / 1599(35.7 \%)$ had a previous diagnosis of osteoporosis. Of these, 70/1051 (7\%) received anti-osteoporosis medication, and $311 / 733(42.4 \%)$ received it post-fracture. Of the total records with information, 65/707 (9.2\%) died the following year of the fracture.

Conclusions. Fracture prevention programs in institutions allow for de- 
tecting patients with fragility fractures, clinical characteristics of these, in addition to strengthening the conditions of a centralized national registry, based on the parameters of the International Osteoporosis Foundation - Capture the Fracture program, through strategies with multidisciplinary personnel.

Key words: osteoporosis, fractures bone, hip fractures, mortality, registries, therapy

\section{INTRODUCTION}

Fragility fractures are those caused by low-energy trauma or falls from standing height, as a consequence of the deterioration of bone microarchitecture and quality caused by osteoporosis. These fractures occur more often in women than in men ${ }^{1}$, and their incidence increases after the fifth decade of life, the hip being the most frequent place, in relation to menopause, with a reported prevalence of 39 to $50 \%$ in women and 13 to $22 \%$ in men. Approximately 3.5 million new cases per year have been reported in Europe, a figure expected to double by $2050^{2,3}$. The impact on post-fracture hip functionality, this being the most frequent, shows a permanent disability of $40 \%$ and an inability to perform daily activities of $80 \%{ }^{4}$. The mortality after the first year of suffering the hip fracture ranges from 15 to $30 \%{ }^{4,6}$. Similarly, the direct cost of treating fragility fractures has been described at USD \$ 7000 per event, regardless of the location of the fracture, with an average of 10 days of hospitalization, and according to calculations made by direct care, the derived costs between 2016 and 2050 could reach USD \$ 228 billion ${ }^{3,7}$. This worrying situation adds to the change in the population pyramid, where the increase in the population over 50 years of age worldwide is evident, impacting the risk factors for osteoporosis, and therefore, fragility fractures. Colombia is no stranger to this reality, given that the prevalence of lumbar osteoporosis has been described in people over 50 years of age around $15.7 \%$, with an annual fragility fracture rate of 8000 to 10,000 cases $^{8}$. Despite having several osteoporosis medications available to them, 8 out of 10 women do not receive treatment in the year following an osteoporosis-related fracture ${ }^{9}$.

This problem has been addressed through the creation of interdisciplinary programs for the early diagnosis and prevention of fragility fractures, such as the Kaiser bone health program, which has shown a $40 \%$ reduction in the incidence of new fractures and $51 \%$ of hip fractures in 3 years ${ }^{10}$. In other reports of studies of fracture patients, after a fracture prevention program was established the number of treated patients increased between 2 and 3 times, compared to the baseline ${ }^{11}$. These initiatives have been led by international organizations, as proposed by the International Osteoporosis Foundation (IOF). One of them, denominated "Capture the Fracture" has had a relevant impact on the prognosis of these patients ${ }^{11}$.

The implementation of these international strategies requires that there be local leaders in each country, in order to provide viability to these projects. These projects have shown reductions both in the incidence of fractures after the first fragility fracture and in post-fracture mortality, which has a direct impact on the costs of care and in the indirect ones that are related to the quality of life of the patients as well as their caregivers. For this reason, the creation of a population registry would give way to a closer knowledge of this critical reality. Additionally, this would turn into a space where the participation of referring institutions that offer comprehensive management of these patients could be socialized at the national level, in order to publicize the behavior of this pathology in our country.

In this context, the Asociación Colombiana de Osteoporosis y Metabolismo Mineral (ACOMM), with the support of the IOF, has joined the initiative of "Capture the Fracture", where it hopes to build a national database and institutionalize fracture liaison services (FLS). This study describes the clinical characteristics of a cohort of patients diagnosed with fragility fractures of 10 FLS in Colombia, constituted in a multidisciplinary manner during one year of follow-up.

\section{PATIENTS AND METHODS}

A descriptive cross-sectional study was conducted, which describes a group of patients diagnosed with fragility fractures, as a result of an initiative of the ACOMM, in order to build the first national registry of fragility fractures, for which 10 centers were invited and each one submitted their respective databases. The research group compiled and consolidated the data in order to determine the most relevant variables for the description of the first registry initiative.

Fragility fracture was defined as the fracture caused by minimal trauma and/or by a fall from standing height. This definition was taken into account by common agreement by the researchers, to determine the selection criteria for each of the records. Selection criteria: all patients with a previously defined fragility fracture diagnosis were included. Exclusion criteria: patients with malignancy or traumatic fractures. Consequently, the study obtained variables including sociodemographic factors, comorbidity, history of osteoporosis by 
densitometry and its previous medical management, history of fragility fracture and location (hip, forearm, humerus proximal, reported by the patient and vertebral fractures diagnosed by radiography), surgical and medical treatment after the fracture, the time between diagnosis and surgical treatment, and mortality within the first year of the fracture. As stated above, 10 health care centers in four cities in Colombia participated in the project: Hospital de San José (Bogotá), Hospital Universitario de La Samaritana (Bogotá), Hospital San Blas (Bogotá), Hospital Universitario San Ignacio (Bogotá), Fundación Santa Fe (Bogotá), Hospital Universitario Clínica San Rafael (Bogotá), Hospital Santa Clara (Bogotá), Hospital Universitario del Valle (Cali), Hospital Universitario San Vicente Fundación (Medellín), and Hospital de Caldas (Manizales). From the matrices sent by the centers, information was consolidated in a database with the common variables that allowed describing the patients and the centers included.

Once the information was consolidated, despite its variability, it was validated against the coding that each center sent, and as a result, a large database was built which included the variables that the centers and the researchers homogeneously considered important for the analysis. For this, a descriptive analysis of the information was performed. The qualitative variables were presented with absolute and relative frequencies, and the quantitative variables were presented with measures of central tendency and dispersion, according to the distribution of the data. The data processing was done in Excel and the analysis in STATA ${ }^{14}$.

With regards to ethical considerations of research with human beings, this registry took into account national regulations (resolution 8430 of 1993) and was classified as a risk-free investigation, taking into account that it deals with information collected retrospectively. In the same way, it was endorsed by the ACOMM academic committee.

\section{RESULTS}

Information was collected from 10 fragility fracture care centers in 4 cities in Colombia, which responded to the call made by ACOMM. The information analysis led to identifying some variables in common, and others that are presented below, but that are not in all the centers, which will be part of the discussion, hoping in the future to homogenize the collection of information. The institutions that participated are reference hospitals that are characterized by attention to pathologies of high complexity, some of them are university, and multidisciplinary hospitals, with the participation of clinicians and orthopedists.
The databases were consolidated, and 1699 patient records were obtained, between 50 and 101 years old, with a female representation of 1334 patients (76.5\%). With regards to weight and height $(n=685)$, a median weight of $60 \mathrm{~kg}$ was determined, with an interquartile range (IQR) of 52-66, while the median size was 1.52 (IQR: 1.48-1.6).

Weight and height were described according to sex, obtaining the following results: female: weight median $59 \mathrm{~kg}$ (IQR: 51-65), height median 1,5 mt (IQR: 1.471.56), and male: weight median $63 \mathrm{~kg}$ (IQR: 55-70), height median 1,64 mt. (IQR: 1.57-1.68).

Among the secondary causes of osteoporosis, the most frequent are: diabetes mellitus, insufficient vitamin $D$ and corticosteroid therapy. The rest of the general characteristics of the population are presented in Table I.

Once patients were evaluated by each center and fragility fractures were diagnosed, different variables that allowed characterizing the population were analyzed. Variables referring to the pathological history and toxicological history were included within which alcohol consumption and smoking were analyzed (Tab. I). Likewise, in the case of the toxicological history, information for alcohol consumption was reported in 872 patients, of which 74 (8.4\%) consumed alcohol (3 or more units of alcohol daily),

Table I. General characteristics of the population.

\begin{tabular}{|c|c|c|}
\hline & $\mathbf{n}$ & $\%$ \\
\hline \multicolumn{3}{|l|}{$\operatorname{Sex}(n=1699)$} \\
\hline Female & 1334 & 76.5 \\
\hline Male & 365 & 21.5 \\
\hline Age - median (IQR †) & 79 & $(70-84)$ \\
\hline $\mathbf{B M I} \ddagger-$ median $(I Q R+)$ & 25.3 & $(22-28)$ \\
\hline \multicolumn{3}{|c|}{ Secondary causes of osteoporosis } \\
\hline \multicolumn{3}{|c|}{ Pathologies } \\
\hline Vit-D insufficiency $\|$ & $145 / 632$ & 22.9 \\
\hline Diabetes & $134 / 1064$ & 12.6 \\
\hline Rheumatoid arthritis & $48 / 980$ & 4.9 \\
\hline Malabsorption syndrome & $14 / 419$ & 3.3 \\
\hline Hypogonadism & $17 / 632$ & 2.7 \\
\hline \multicolumn{3}{|l|}{ Pharmacotherapy } \\
\hline Corticosteroids ** & $61 / 788$ & 7.7 \\
\hline Anticonvulsants & $13 / 296$ & 4.4 \\
\hline Antipsychotics & $20 / 460$ & 4.3 \\
\hline Antidepressants & $7 / 184$ & 3.8 \\
\hline \multicolumn{3}{|l|}{ Toxicological history } \\
\hline Smoking & $251 / 1147$ & 21.9 \\
\hline Alcohol consumption & $73 / 872$ & 8.4 \\
\hline Mortality * & $63 / 673$ & 9.3 \\
\hline
\end{tabular}

$\dagger$ interquartile range; $\neq$ body mass index; *after a year of fracture; ${ }^{*} \geq 5 \mathrm{mg} /$ day for 3 months or equivalent, $\| \leq 30 \mathrm{ng} / \mathrm{dl}$. For the variables: decondary causes of osteoporosis, pharmacotherapy, toxicological history and mortality, in the denominator was taken into account the total number of patients with reported records. 
Table II. Prescription details of osteoporosis medications prior to the diagnosis of fragility fracture and after hospital treatment.

\begin{tabular}{|l|c|c|}
\hline Medication & $\begin{array}{c}\text { Before } \mathbf{f} \\
\mathbf{n}(\%)\end{array}$ & $\begin{array}{c}\text { After } \mathbf{f} \\
\mathbf{n}(\%)\end{array}$ \\
\hline Calcium & $75(47.7)$ & $262(62.9)$ \\
\hline Vitamin D3 & $32(20.3)$ & $72(17.3)$ \\
\hline Alendronate & $42(26.7)$ & $37(8.8)$ \\
\hline Ibandronate & $2(1.2)$ & $1(0.2)$ \\
\hline Risedronate & $2(1.2)$ & $1(0.2)$ \\
\hline Zoledronic acid & $9(0.9)$ & $83(20)$ \\
\hline Strontium ranelate & $0(0)$ & $3(0.7)$ \\
\hline Raloxifene & $0(0)$ & $0(0)$ \\
\hline Teriparatide & $9(5.7)$ & $110(26.4)$ \\
\hline Denosumab & $6(5.7)$ & $76(18.2)$ \\
\hline
\end{tabular}

Patients with prescription medication prior to fragility fracture $\dagger(n=162)$, and with prescription after hospital discharge $\ddagger(n=439)$.

and for smoking in 1147 cases of which 251 (21.9\%) had this antecedent. When evaluating the history of previous fragility fractures, $1484(87.3 \%)$ records were reported of which 581 (39.1\%) reported having suffered a fracture. The antecedents related to the causes of secondary osteoporosis were described, which included pathologies and drug uses that have been shown to be a direct cause of loss of bone density, the detail is described in Table I.

Regarding the antecedents of osteoporosis, it was determined that of 1599 (94.1\%) patients who reported information, 570 (35.7\%) had a previous diagnosis of osteoporosis, and of these, it was possible to identify that 180 (31.5\%) were receiving pharmacological treatment (anti-osteoporosis, calcium and vitamin D drugs), this means that a previous pharmacological management was prescribed to $10.6 \%$ of the total of the registries.

Of the 1051 records with a report of administration of osteoporosis medication prior to fragility fracture 162 $(15.4 \%)$ received treatment. In the case of the posthospital prescription, 733 patients were reported of which 439 (59.9\%) received medical treatment. Of these patients, only $70(7 \%)$ received anti-osteoporosis medication (antiresorptive or osteoforming therapy), and after the fracture, 311 (42.4\%). The details of the medications used are presented in Table II.
In relation to sex and age, the median age in years for women was 79 (IQR: 70-85), minimum age of 50 and a maximum of 101 , similar to that of men, 79 (IQR: 71-84), minimum age of 50 and a maximum of 99 . Age was categorized in order to find out the frequencies of presentation, finding that 108 (6.3\%) were under 60, 326 (19.2\%) were between 60 and 70, and 1265 (74.4\%) were older 70 years old age was also explored according to the location of the fracture, which is presented in Table III. When describing fragility fractures, an anatomical distribution was found, and it is presented in Figure 1.

When evaluating surgical management, information was reported on 677 (39.8\%) cases, of which 541 (79.1\%) were taken to surgery, and the time in days from the diagnosis of fragility fracture to the surgical procedure was presented as follows: between 1 and 2 days, 182 (40\%), 3 to 5 days 162 (35.6\%), 6 to 9 days 87 (19.1\%) and more than 9 days 24 (5.2\%).

The proportion of patients with a history of osteoporosis and previous treatment for this pathology was explored, according to the anatomical location of fracture due to current fragility (Tab. IV).

Of the patients with a history of osteoporosis, 379 $(74.5 \%)$ reported having had a previous fragility fracture. With respect to mortality, clarifying that this study does aim to determine causality, it was determined that of the total information reported $(n=707), 65(9.2 \%)$ died during the first year after the fracture. Similarly, mortality was calculated according to the fracture site, finding that of the total number of deceased patients $(n=63)$, $40(61.6 \%)$ had hip fractures, $8(12.4 \%)$ in the proximal humerus, $8(12.4 \%)$ in wrist, $5(8 \%)$ in vertebral, and 4 $(6.1 \%)$ other fractures. Of the total number of patients with hip fracture, 40 died (8.1\%).

\section{DISCUSSION}

Fragility fractures have become a public health problem worldwide, which is related to the increase in the population over 50 , which is susceptible to osteoporosis. These changes are directly related to the increase in the elderly population and the decrease in perinatal

Table III. Age according to fracture site.

\begin{tabular}{|l|c|c|c|c|c|c|}
\hline \multicolumn{7}{|c|}{ Fracture location } \\
\hline Age & Hip & Vertebral & $\begin{array}{c}\text { Proximal } \\
\text { humerus }\end{array}$ & Wrist & Others & $\begin{array}{c}\text { Total } \\
(\mathbf{n}=\mathbf{1 6 7 8})\end{array}$ \\
\hline$<\mathbf{6 0}$ & $43(39.8)$ & $18(16.7)$ & $4(4.6)$ & $35(32.4)$ & $7(6.5)$ & $108(6.4)$ \\
\hline $\mathbf{6 1 - 7 0}$ & $163(51)$ & $87(27.2)$ & $11(3.4)$ & $44(13.7)$ & $15(4.7)$ & $320(19)$ \\
\hline$>\mathbf{7 0}$ & $770(61.6)$ & $214(17.1)$ & $53(4.2)$ & $135(10.8)$ & $78(6.2)$ & $1142(68)$ \\
\hline
\end{tabular}

$\mathrm{n}(\%)$ 


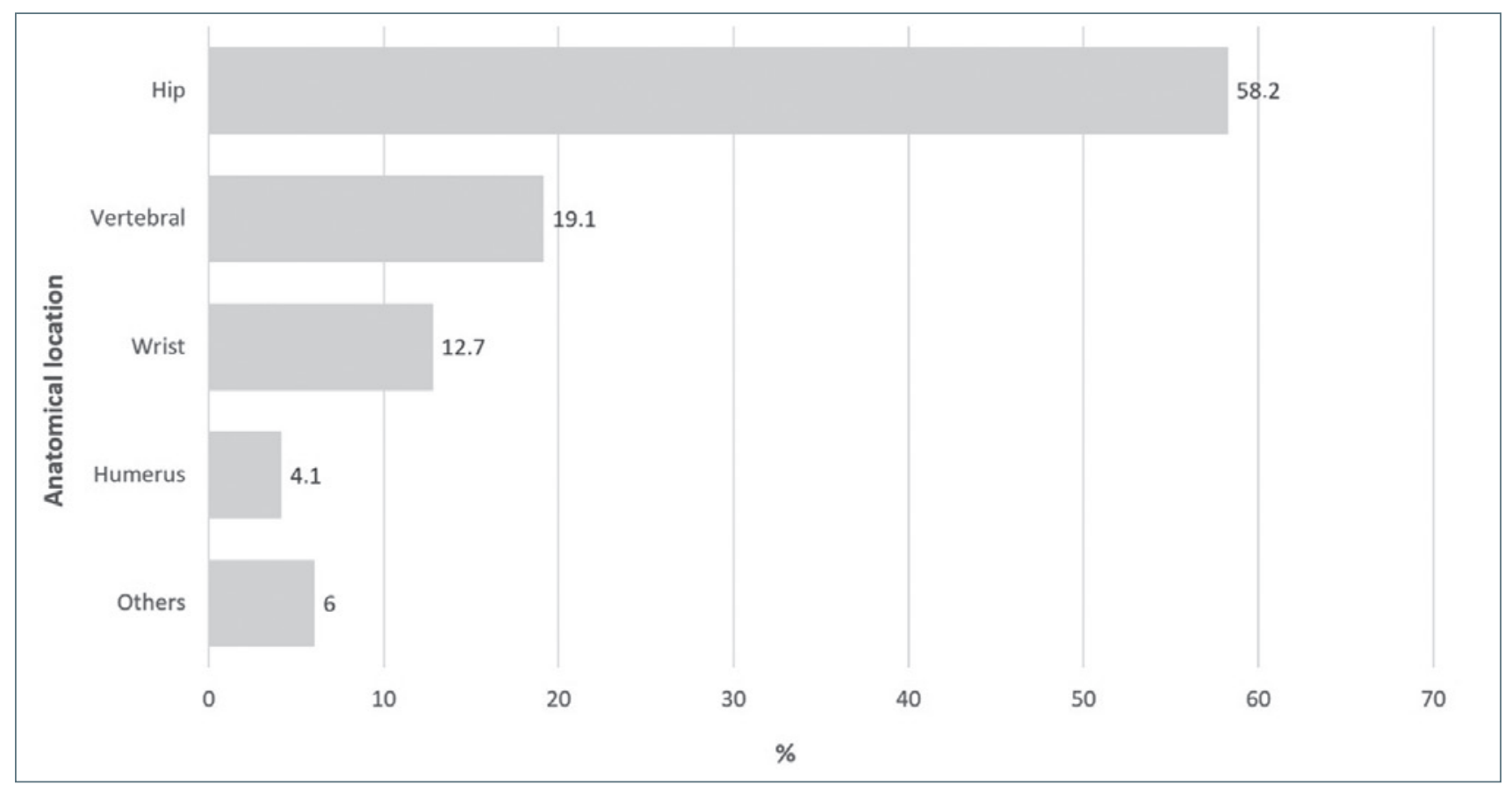

Figure 1. General anatomical description of fragility fractures.

Table IV. Anatomical location of the fractures according to the history of osteoporosis and previous medical treatment.

\begin{tabular}{|l|c|c|c|c|c|c|}
\hline \multicolumn{2}{|c|}{ Previous pharmacological treatment for osteoporosis } & \multicolumn{4}{c|}{ History of osteoporosis } \\
\hline Anatomical location & YES & NO & Total & YES & N0 & Total \\
\hline Hip & $98(14.7)$ & $557(85.3)$ & 655 & $203(22.3)$ & $686(77.1)$ & 889 \\
\hline Vertebral & $31(24.4)$ & $96(75.6)$ & 127 & $221(69.4)$ & $95(30.1)$ & 316 \\
\hline Humerus & $6(11.7)$ & $45(88.3)$ & 51 & $23(33.3)$ & $46(66.6)$ & 69 \\
\hline Wrist & $17(10,1)$ & $152(89.9)$ & 169 & $65(31.5)$ & $141(68.5)$ & 206 \\
\hline Others & $10(20,4)$ & $39(79.6)$ & 49 & $40(40.8)$ & $58(59.2)$ & 98 \\
\hline
\end{tabular}

$\mathrm{n}(\%)$

mortality, showing a transformation in the demographic pyramid $^{12}$. It is estimated that by 2006 there were 200 million cases of osteoporosis, with projections of 20 million new cases by 2020, where the distribution by age range increases the prevalence as follows: $10 \%$ between 60-70 years, 20\% between $71-80$ years, $40 \%$ between $81-90$ years and $66 \%$ in people over 90 years ${ }^{12}$. In the last decade, in Europe, Asia, and America, it has been identified that osteoporosis has not only increased its prevalence but has become one of the pathologies with more demand in health services, above cancer and arthritis rheumatoid, which historically had been diseases that characterized the elderly population ${ }^{13}$.

According to the above, and analyzing the results of this study, only $35.6 \%$ of the population had a previous diagnosis of osteoporosis, and of these, $40 \%$ had been receiving treatment, which contrasts with a descriptive cross-sectional study of a university hospital in Bogotá, Colombia, published in 2019, which included 111 patients diagnosed with fragility fractures, of which 33 patients $(21 \%)$ had a history of osteoporosis ${ }^{3}$. This evidences the great problem that a large part of the Colombian population probably faces, since $70 \%$ do not know their disease, and therefore, are not aware of the risk of a fracture. When contrasting our results with studies reported by Cohen and Terence, who report previous diagnoses of osteoporosis in patients with $45 \%$ fragility fractures, it is evident that there is a need to strengthen the conditions of a national and centralized registry, based on the parameters of the IOF program - Capture the Fracture, as well as the urgency of implementing in a homogeneous way the strategies of the same program, which could reach higher prevention percentages, hoping to reduce fracture, re-fracture and mortality fracture rates ${ }^{14}$. 
By the same token, the identification of risk factors that have proven to be predictors of mortality in patients with fragility fractures allows their intervention in a timely manner. Among these factors are advanced age, smoking, low bone mineral density and presence of comorbidities. These variables, which were mostly included in our study, could be the starting point to estimate the patient's risk of suffering an osteoporotic fracture, associated mortality and disability in our population and thus recognize its impact on the health system.

When analyzing the data obtained in all fragility fractures of different anatomical locations, it is observed that only $35.6 \%$ had a previous diagnosis of osteoporosis, even though the percentage of previous fragility fracture was $39.1 \%$. It is striking that mainly in the hip fracture (58.6\%), and in the majority of cases in which the diagnosis of osteoporosis was known, there was no prior antiresorptive or osteoforming treatment. This correlates with the study by Cuddihy M-T, in which 8 out of 10 women did not receive treatment in the year following an osteoporotic fracture ${ }^{9}$.

The establishment of medical treatment for osteoporosis, along with other measures is necessary to avoid subsequent fractures, because after the osteoporotic fracture occurs, there is an $86 \%$ risk of subsequent refractures ${ }^{15}$.

Regarding the time between the diagnosis and the surgical procedure, it is important to note that this period is directly related to the prognosis of the patient, specifically with morbidity and mortality, taking into account in-hospital infections, injuries due to long periods of immobility (thrombus embolisms, pressure sores, and psychiatric pathologies, among others), and the impact on quality of life ${ }^{16,17}$. Thus, the recommendation according to the literature, about the ideal time, is that the surgical procedure is performed between 24 and 48 hours after diagnosis. This is argued in studies where medians between 1.8-3 days are reported, which contrasts with the results of this study where a median of 4 days was evidenced (IQR: 1-10), which implies a review of the processes, since $60 \%(n=455)$ of the population was taken to surgery 72 hours after. This reflection obliges fragility fracture care centers to improve the opportunity for attention and reduce the time for surgery, once the indication for surgery is identified ${ }^{18,19}$.

The post-fracture anti-osteoporosis treatment was $43.6 \%$ similar or greater than expected in the different programs for prevention of second fragility fracture, as observed in other studies of Gardner with an increase to $42 \%(p=0.036)$, Davis, $68 \%(p<0.05)$ and Majumdar $52 \%(p<0.001)^{11}$. In our study, before the fracture, only $7.4 \%$ received antiresorptive or osteoforming therapy, the majority received calcium and vitamin D; after the fracture, within each FLS and in the data that were recorded, the percentage that received antiosteoporosis treatment rose to $43.6 \%$, in contrast to a local study in which a post-fracture treatment rate of $10 \%$ was found in a population of 111 patients with fragility fractures ${ }^{3}$. An explanation for the change in the treatment gap before and after the fracture is the elaboration and dissemination of the second Colombian consensus of postmenopausal osteoporosis, in which management guidelines are given for patients at high risk of fracture, such as those have suffered a previous osteoporosis fracture, or are elderly; This is how medications such as zoledronic acid, denosumab and teriparatide increase markedly in their percentage of post-fracture use ${ }^{20}$. Data on the reduction of the incidence of re-fracture could not be analyzed in our study, as a $40 \%$ reduction in the incidence of hip fracture is reported in the Kaiser bone health program (California-USA), or as reported by Marsh, D, of a re-fracture risk reduction of up to $51 \%$ after the implementation of a FLS in 3 years ${ }^{11}$.

Notably, the most common type of fracture in our study at any age was the hip, contrary to what is observed in previous studies, in which the fracture of the distal forearm predominates in women under 60 years of age and the hip, in those older than $70{ }^{21}$. This could be explained because, most patients are operated or hospitalized, unlike what happens with fractures of the distal and vertebral forearm. It is also noteworthy that our study, compared to the LAVOS study (Latin American Vertebral Osteoporosis Study), which included five countries: Argentina, Brazil, Colombia, Mexico and Puerto Rico, a very similar general prevalence for vertebral fracture was found: $14 \%{ }^{8}$.

Hip fractures should be considered a relevant cause of mortality, since in men and women they cause 37 and $25 \%$ respectively, one year after the fracture occurred ${ }^{12}$. There is also the impact of fragility fractures on quality of life such as the return of functionality, which is only achieved in 50\% of cases, the presence of chronic pain in $80 \%$ and the probability of $60 \%$ of presenting new fragility fractures ${ }^{12}$. In our study, mortality was $9.1 \%$, within the year following the fracture, and when evaluating by anatomical location, the hip was the most frequent, being present in 63\% of deceased patients. Mortality in hip fracture patients was lower than reported in the literature, with a percentage of $8.1 \mathrm{com}$ pared to 15 to $30 \%$ in the first year after the fracture occurred ${ }^{4-6}$. It is important to mention that less than half of the records reported all data. This mortality is lower than that reported in other studies, possibly due to lack of patient follow-up, since many of them are not seen again in the institution where they were operated or admitted, with the consequent under-recording, and due to positive factors such as impact of the increase in the number of patients with post-fracture treatment 
and reduction in the time elapsed from admission to surgery that was $1-5$ days, by $76 \%$. The functionality variables of 2 ortho-geriatric centers were not included, because they were not the variables requested from all other SEFs, however, it is important, in the future, to consider including them.

Gittoes et al. not only mentioned the importance of these comprehensive care programs for fragility fractures, but they suggested some elements that should be part of both the registries and the programs ${ }^{15}$ : identifying patients with fragility fractures for care and treatment, building population records to analyze the behavior of the associated risk factors and the prognostic factors of our population, structuring pedagogical strategies for patients to work together to prevent fragility fractures, timely intervening in the pharmacological and non-pharmacological management for osteoporosis and the prevention of second fractures, and structuring interdisciplinary programs at all levels of care to ensure patient coverage.

It is important to mention that these strategies have proven effective since they reduce the incidence of fragility fractures by $51 \%$, second fragility fractures by $80 \%$ and mortality by $33 \% 22$.

Although the contribution in the national epidemiology of the characterization of fragility fractures, and the impact of SEFs on the therapeutic gap are the main strengths of our study, its weaknesses are based on the fact that the registration of the information was not homogeneous, as the variables included are not similar in all centers by collection characteristics. This heterogeneity did not allow for establishing the main comorbidities as well as, whether or not there was a risk of falls program, depending on its location, and the follow-up of treatment, re-fracture, and death.

All of the above, not only obliges our hospitals and the health system to consider the formal implementation of the programs but also to build a registry to monitor the behavior of fragility fractures since the contribution of consolidated statistical data would allow establish population parameters as possible explorations in the associations of variables that would be collected continuously and that would probably be representative of the Colombian population. Similarly, the analysis of this registry would give way to the ACOMM as leader of the registry to be able to elaborate statements for making homogeneous decisions and contribute elements to public policy as scientific unionization. This first description of patients with a diagnosis of FF would be the gateway to standardize the registry, constitute a follow-up strategy and use the information to improve the quality of life of patients, in addition to supporting aspects in public policy to reduce barriers to access in this disease ${ }^{11}$.

\section{CONCLUSIONS}

This is the first Colombian registry of fractures, which identifies demographic data, diagnosis of osteoporosis, fracture, and treatment, prior to the fracture, as well as post-treatment, mortality and comorbidity. Given the heterogeneity of the data, it is necessary to strengthen the conditions of a centralized national registry, based on the parameters of the IOF - Capture the Fracture program, as well as prioritize the homogeneous implementation of the strategies of the same program, which could reach percentages of higher prevention, hoping to reduce the rate of fractures due to fragility, re-fracture and mortality. In that order of ideas, it is imperative to propose strategies in each institution, and involve more multidisciplinary personnel for the excellent performance and achievement of goals in each FLS. It is important to clarify that the goals of this study was not to establish causality among variables, but to describe the patients' clinical characteristics, including the mortality of patients with FFs.

\section{Limitations}

This study was built upon the initial proposal for a national FF registry. However, the heterogeneity in the report of included variables did not allow for gathering the complete records of all 10 centers.

\section{Ethical consideration}

This manuscript was classified as a risk-free investigation because the information was collected retrospectively. The ethical considerations of research with human beings were based on national regulations (resolution 8430 of 1993) and were endorsed by the ACOMM academic committee.

\section{Acknowledgement}

We are grateful for the collaboration of all the doctors from the hospitals and clinics who contributed with the data, and to ACOMM and Eli lilly for their support in the development of this project.

\section{Details of financial/conflict of interest}

This study was funded by the Asociación Colombiana de Osteoporosis y Metabolismo Mineral (ACOMM) and by Lilly laboratories (2019). The authors and FLSs did not receive any fees for their participation in this study. None of the authors declares conflicts of interest.

\section{Author contributions}

All the authors contributed in the development of this manuscript. 


\section{References}

1 Hermoso de Mendoza MT. Clasificación de la osteoporosis: factores de riesgo. Clínica y diagnóstico diferencial. Anales del Sistema Sanitario de Navarra 2003;26:29-52.

2 Lim J-Y. Fragility fracture care: an urgent need to implement the integrated model of geriatric care. Ann Geriatr Med Res 2019;23:1-2. https://doi.org/10.4235/agmr.19.0011

3 Fernandez-Avila DG, Rincon-Riano DN, Pinzon DF, et al. Low rate of densitometric diagnosis and treatment in patients with severe osteoporosis in Colombia. Arch Osteoporos 2019;14:95. https://doi.org/10.1007/ s11657-019-0646-6

4 Cooper $\mathrm{C}$. The crippling consequences of fractures and their impact on quality of life. Am J Med 1997;103:12S17S; discussion 17S-19S. https://doi.org/10.1016/ s0002-9343(97)90022-x

5 Medina A, Rivera A, Butista K, et al. Características clínicas de los pacientes con fracturas por fragilidad. Revista Repertorio de Medicina y Cirugía 2018;27:30-35.

6 Dang DY, Zetumer S, Zhang AL. Recurrent fragility fractures: a cross-sectional analysis. J Am Acad Orthop Surg 2019;27:e85e91. https://doi.org/10.5435/jaaos-d-17-00103

7 Cohn MR, Gianakos AL, Grueter K, et al. Update on the comprehensive approach to fragility fractures. J Orthop Trauma 2018;32:480-490. https://doi.org/10.1097/ bot.0000000000001244

8 Clark P, Cons-Molina F, Deleze M, et al. The prevalence of radiographic vertebral fractures in Latin American countries: the Latin American Vertebral Osteoporosis Study (LAVOS). Osteoporos Int 2009;20:275-282. https://doi. org/10.1007/s00198-008-0657-4

9 Cuddihy MT, Gabriel SE, Crowson CS, et al. Osteoporosis intervention following distal forearm fractures: a missed opportunity? Arch Intern Med 2002;162:421-426. https:// doi.org/10.1001/archinte.162.4.421

10 Dell R. Fracture prevention in Kaiser Permanente Southern California. Osteoporos Int 2011;22(Suppl 3):457-460. https://doi.org/10.1007/s00198-011-1712-0

11 Marsh D, Akesson K, Beaton DE, et al. Coordinator-based systems for secondary prevention in fragility fracture patients. Osteoporos Int 2011;22:2051-2065. https://doi. org/10.1007/s00198-011-1642-x
12 Sanchez-RieraL, Wilson N. Fragility fractures \& their impacton older people. Best Pract Res Clin Rheumatol 2017;31:169191. https://doi.org/10.1016/j.berh.2017.10.001

13 Johnell O, Kanis JA. An estimate of the worldwide prevalence and disability associated with osteoporotic fractures. Osteoporos Int 2006;17:1726-1733. https://doi. org/10.1007/s00198-006-0172-4

14 Ong T, Kantachuvesiri P, Sahota O, et al. Characteristics and outcomes of hospitalised patients with vertebral fragility fractures: a systematic review. Age Ageing 2018;47:1725. https://doi.org/10.1093/ageing/afx079

15 Huntjens KM, van Geel TA, van den Bergh JP, et al. Fracture liaison service: impact on subsequent nonvertebral fracture incidence and mortality. J Bone Joint Surg Am 2014;96:e29. https://doi.org/10.2106/jbjs.I.00223

16 Vallejo-González S, Martínez J, Benítez-Mejía J, et al. Clinical and epidemiological characteristics of patients with fragility fractures: are we doing things right? Act Med Col 2020;45:1-6.

17 Alarcón T, González-Montalvo J, Mauleon J, et al. Demora del tratamiento quirúrgico de la fractura de cadera: un suma y sigue de problemas. Rev Esp Sal Pub 2015;89:117-118.

18 Nikkel E, Kates L, Schreck M, et al. Length of hospital stay after hip fracture and risk of early mortality after discharge in New York state: retrospective cohort study. BMJ 2015;351: h6246.19. https://doi.org/10.1136/bmj. h6246

19 Nordström P, Gustafson Y, Michaëlsson K, et al. Length of hospital stay after hip fracture and short term risk of death after discharge: a total cohort study in Sweden. BMJ 2015;350:h696. https://doi.org/10.1136/bmj.h696

20 Medina A, Rosero O, Rueda P, et al. II consenso colombiano para el manejo de la osteoporosis posmenopáusica. Rev Colomb Reumato 2018;25:184-210.

21 Watts N. Prevention of osteoporosis: the role of primary physicians. J Fam Pract 1991;23:261-264.

22 IOF. Gaps and solutions in bone health. A global framework for improvement, 2015 (https://www.iofbonehealth. org/thematic-report-2016). 